CASE STUDY

\title{
An undergraduate peer mentoring program at a Canadian university: Impact on student learning as perceived by instructors, peer mentors, and students
}

Dan S. Petrescu, Department of Chemistry and Tomlinson Project for University-Level Science Education (TPULSE), McGill University, Montreal, Canada.

Armin Yazdani, Department of Neuroscience and Tomlinson Project for University-Level Science Education (TPULSE) and Office of Science, McGill University, Montreal, Canada.

Cassidy R. VanderSchee, Department of Chemistry, The King's University, Edmonton, Canada.

Christopher A. Bailey, Department of Kinesiology and Physical Education and Tomlinson Project for University-Level Science Education (TPULSE), McGill University, Montreal, Canada.

Faygie Covens, Tomlinson Project for University-Level Science Education (TPULSE), McGill University, Montreal, Canada.

*David N. Harpp, Department of Chemistry and Tomlinson Project for University-Level Science Education (TPULSE), McGill University, Montreal, Canada.

Contact: david.harpp@,mcgill.ca

\section{ABSTRACT}

Large undergraduate courses make it difficult for students to achieve learning outcomes, in part due to the lack of resources available to course instructors to support student learning in these intimidating and often impersonal settings. One way to support instructor teaching and student learning is the implementation of undergraduate peer mentoring programs, which capitalize on the Students-as-Partners framework. Undergraduate mentors' relatability to their peers and their mastery of the course content make them excellent resources. This paper describes the development and implementation of a university-wide undergraduate peer mentoring program at McGill University in Canada and its impact on student learning as perceived by three populations: instructors, peer mentors, and students. Data on perceived learning was gathered through qualitative surveys. This case study presents one implementation model that may guide and inform the implementation of similar programs at other higher education institutions. 


\section{KEYWORDS}

peer mentoring, students as partners (SaP), undergraduate teaching, STEM education, qualitative surveys

\section{Peer instruction as a Students-as-Partners framework}

While students have been traditionally viewed as the recipients of knowledge, they can also participate as full intellectual partners in the learning and teaching process. The Studentsas-Partners (SaP) framework empowers students as partners in the design of teaching and learning programs rather than viewing them only as knowledge consumers (Bryson, 2016; Healey et al., 2018; Mercer-Mapstone et al., 2017). There are many ways in which the SaP framework can be integrated into the classroom, and there has been a steady increase in the number of SaP programs across North America over the last decade to democratize higher education (Healey et al., 2018). Peer instruction has been identified as one such effective student-centered instructional strategy that actively engages the learner in a wide range of classroom and laboratory settings across STEM disciplines (Crouch \& Mazur, 2001; Crouch et al., 2007; Fagen et al., 2003; Mazur, 2008; Schell \& Mazur, 2015). Particularly, peer instruction has proven beneficial in promoting deeper learning in large STEM courses with limited resources (Crouch, 2009; Danker, 2017; Zher et al., 2016).

One approach to enhancing the available resources to students is the development of formal peer instruction programs that rely on undergraduate teaching assistants (UTAs). UTAs do not replace instructors or graduate teaching assistants (GTAs) but rather complement their roles through their relatability to students, familiarity with course content, and studentcentered perspective, thereby contributing to an improved learning landscape for students (Fingerson \& Culley, 2006). UTAs have already demonstrated a successful track record in improving student learning and achievement in large STEM courses (Philipp et al., 2016; Wheeler et al., 2017). Such peer instruction programs have also empowered undergraduate students to act as mentors for improving the student learning experience and for helping their peers navigate the transition to university (Colvin \& Ashman, 2010; Hill \& Reddy, 2010; Smith, 2008).

\section{The Tomlinson Engagement Award for Mentoring (TEAM) program}

With over 24,000 undergraduate students, McGill University is an example of a large research-intensive university that offers very large STEM courses. While isolated peer instructional approaches had been previously employed in individual courses, no large-scale peer mentorship program that adopted the SaP framework had been established throughout the university. Historically, instructors were restricted to hiring unionized GTAs, and the number of GTAs was regulated by departmental budgets. As students were traditionally seen as the recipients of knowledge, rather than participants in the knowledge creation process, they had rarely been envisaged as formal mentors to their peers. This top-down approach creates a power dynamic that discourages students from taking ownership of and responsibility for their 
learning and presents instructors and GTAs as the ultimate authority with regards to the learning process.

Recognizing the potential benefits of implementing a university-wide program which adopts the SaP framework, McGill University established the TEAM (Tomlinson Engagement Award for Mentoring) program in 2013. In this case study, we describe the development, growth, and impact of the TEAM program using qualitative surveys.

\section{METHODOLOGY: DATA COLLECTION AND DATA ANALYSIS}

At the start of each semester, course instructors submitted an application form to the Faculty of Science that included the course, department and faculty that hosted the student mentors, and the number of mentors requested. These data were compiled for each fall and winter semester between Fall 2013 and Winter 2019. Except for this application form, the completion of all other surveys was optional for course instructors, mentors, and students.

During a training session organized at the start of each semester, mentors were surveyed about their reasons for applying to the program and what they perceived as the most helpful components of the training. These data were collected anonymously using an online polling software (Socrative, Showbie Inc.) for each fall and winter semester between Fall 2016 and Winter 2019.

At the end of the semester, course instructors and mentors were surveyed via email using a feedback form. Instructors were surveyed about their perception of the support provided by the mentors to them and to their students. Mentors were surveyed about the tasks assigned to them, their time commitment throughout the semester, their perception of the support they provided to the students, and the types of support they believed were most effective at promoting student learning. These data were collected for each fall and winter semester between Fall 2014 and Winter 2017 and were anonymized upon receipt.

At the end of the semester, students were surveyed about the support provided to them by mentors throughout their semester. These data were collected anonymously using McGill University's course evaluation software (Mercury Course Evaluation, McGill University) during the Fall 2018 and Winter 2019 semesters.

Responses with pre-defined, Likert-scale, or open-ended responses were analyzed quantitatively. The proportions of each response category were calculated and expressed as a percentage of total respondents. The means of category proportions across all semesters (with semester-to-semester standard deviations) are reported. Open-ended responses were first analyzed qualitatively via deductive content analysis using an online software tool (QCAmap, Association for Supporting Qualitative Research) in order to identify themes that could be used as response categories. Some representative open-ended responses were selected as testimonies and are reported in the form of direct quotations.

\section{DEVELOPMENT AND IMPLEMENTATION OF THE TEAM PEER MENTORING PROGRAM}

\section{Program description and growth}

The TEAM program offers undergraduate students, under the supervision of a course instructor, the opportunity to mentor their peers in a course they have previously taken. By 
partnering instructors with students, the program takes advantage of students' unique perspective on the course as well as their relatability to their peers. As a result, mentors and students become actively involved in the teaching and learning process, while course instructors receive additional support in teaching very large classes.

In its first iteration, the TEAM program counted 114 student mentors in 49 courses (Figures 1 and 2). As of 2020, the program has grown to over 800 mentors in more than 160 courses, with nearly 3,100 mentorships awarded since its inception. Originally intended to serve only STEM courses, the success of the TEAM program has led to the controlled expansion to non-STEM courses in the fall of 2015.

\section{Figure 1. Growth of the TEAM mentor population and TEAM courses}

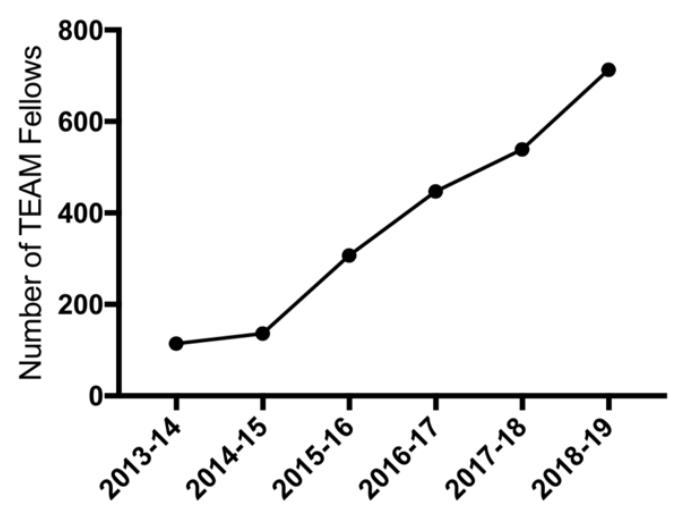

Figure 2. Growth of TEAM courses, including STEM and non-STEM breakdown

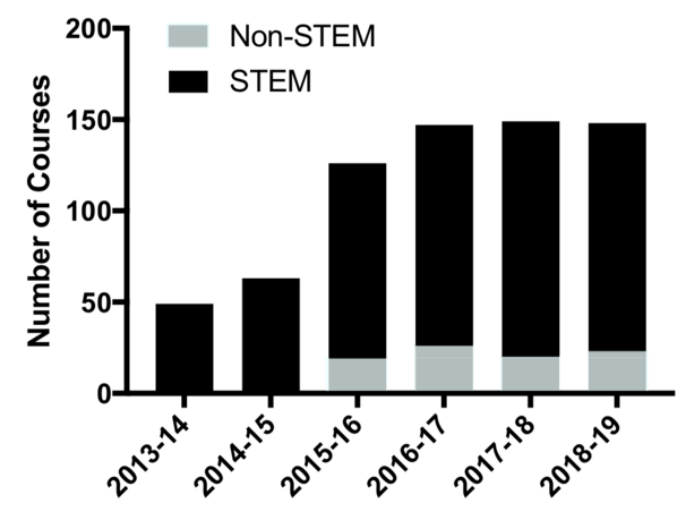

The growth data shows that the program has grown in two phases (Figures 1 and 2). The first 3 years saw a rapid growth in the number of TEAM mentors, the number of courses, and an expansion to non-STEM departments. During this period, the program gained reputation as an additional resource and was adopted by an increasing number of instructors. In turn, the last 3 years have seen a plateauing in the number of courses with TEAM awardees, primarily due to limited program funding. During this period, funding became limited to courses and departments that had previously awarded TEAM mentors. Remarkably, while the number of 
courses had plateaued, the number of TEAM awardees kept growing at a steady rate, indicating a large increase in the number of mentors per course. This suggests that after its initial expansion, the program gained support amongst instructors who have had time to experience the benefits of working with mentors. The growth data is direct evidence of the success of and need for this type of educational program at McGill University. Given sufficient funding, program growth will no doubt continue and reach new courses and departments.

\section{Peer mentor recruitment}

To become TEAM mentors, students must be selected by their course instructor on the basis of their course performance and initiative. Typically, instructors award students who have: (a) regularly and deeply engaged with the course material and their peers, (b) displayed leadership and proactive behavior in leading class discussions and/or organizing study sessions, (c) sought out help and formed an academic relationship with their GTAs and/or instructor, or (d) completed their course with outstanding grades. TEAM mentors are responsible for a variety of tasks for an average commitment of 25-30 hours per course, for which they receive a $\$ 300$ award. This award is funded internally by an endowment made to McGill University to support the development and dissemination of evidence-based teaching practices.

Typically, the TEAM program introduces students to their first formal teaching experience, considering that teaching opportunities for undergraduates remain few. Indeed, the majority of students surveyed reported pursuing the TEAM program to gain teaching experience or simply because they liked the course (Figure 3). Interestingly, very few students reported pursuing the program for the award money. These results point to more intrinsically motivated students who seek out a teaching experience and a professional development opportunity out of personal interest.

Figure 3. Mentors' reasons for applying to the TEAM program, as self-reported

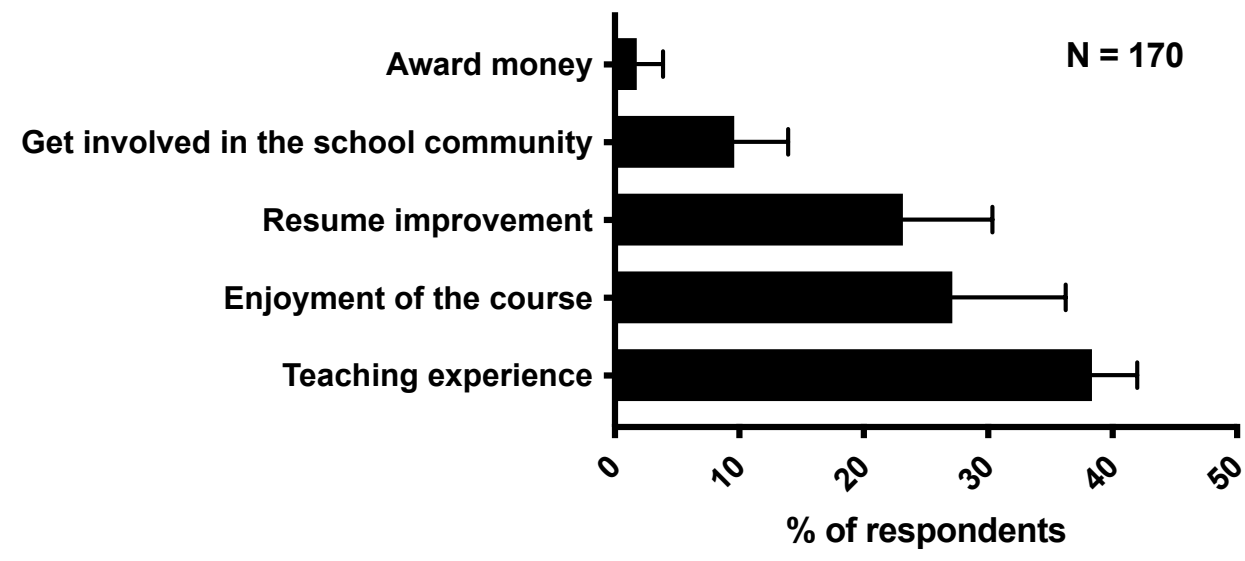

\section{Peer mentor tenure}

Throughout their TEAM experience, mentors are responsible for a variety of tasks assigned by their instructors. At the end of the semester, TEAM mentors indicated that their most commonly assigned tasks included leading or participating in a tutorial or exam review 
session, one-on-one tutoring, and monitoring online support of learning (Figure 4). Considering that the TEAM experience usually constitutes the mentors' first formal teaching experience, it was surprising to learn that course instructors entrusted such responsibilities to undergraduates. In addition, a sizeable fraction of mentors (15\%) also participated in the design of test or assignment questions. Question design is arguably one of the most challenging tasks for instructors and requires subject mastery as well as an understanding of the steps involved in solving problems. For students to engage with this task is a direct testimony of their motivation, competence, and insight into their own learning process. The support of in-class activities or laboratory sessions represented a smaller fraction of the tasks assigned but offered mentors the opportunity to interact with students in other settings such as large lecture halls and laboratories.

Figure 4. Tasks performed by mentors throughout the semester, as self-reported

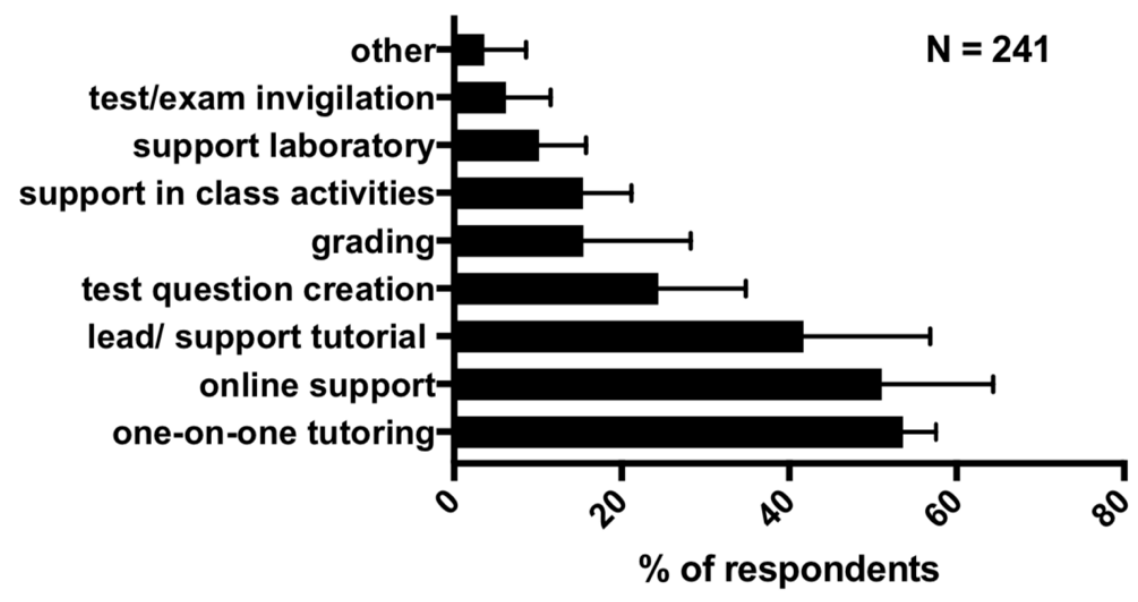

The feedback form also revealed that mentors worked an average of 29 hours per semester ( $n=136$ mentors). This average aligns well with the $25-30$-hour semester involvement expected from mentors. However, the very large standard deviation ( \pm 13 hours) indicates that a large fraction of mentors worked either significantly more or significantly less than the average mentor. Therefore, instructors could be encouraged to more closely monitor the work of their TEAM mentors and to provide more meaningful and suitable responsibilities to mentors reporting fewer hours.

\section{Peer mentor training}

At the beginning of the semester, TEAM mentors attend an optional but recommended 90-minute training session to ensure that, despite the differences between their assigned courses and tasks, mentors are equipped with appropriate tools to succeed in their mentoring experience. The training is designed to be highly interactive through the use of case studies, open-ended questions, clicker-type polls, and think-pair-share activities in order to engage the trainees and encourage them to raise concerns and questions related to their upcoming mentoring experience. Mentors discuss the effectiveness of various pedagogical strategies while collaboratively working through a series of scenarios that challenge their mentoring skills. 
Topics covered include mentorship, professionalism, communication, expectations of the TEAM program, creation and participation in a learning community, and the teaching and learning resources available at McGill University.

Mentors were asked to comment on the most helpful components of the training in an open-ended prompt. In the latest surveyed training session in the Winter 2019 semester, four representative mentors responded the following:

- "[The most helpful component of the training was] how to answer questions, establish a role and communicate within the course." (Training Attendee 1)

- "[The most helpful component of the training was] the interactive aspect of the training! Learning from each other is the best way of learning about mentorship situations." (Training Attendee 2)

- "I feel like the most helpful part of the training were the scenarios on how to approach and communicate with different types of students when they come up to you." (Training Attendee 3)

- "The Q\&A was helpful, as well as talking about the [learning] community." (Training Attendee 4)

\section{IMPACT OF THE TEAM PEER MENTORING PROGRAM}

\section{Instructors' perception of mentors' impact on student learning}

At the end of the academic semester, the course instructors were solicited for feedback about the TEAM program. Results revealed that an overwhelming majority of instructors strongly agreed or agreed that the TEAM mentor helped them and their students, while only a very small minority disagreed or reported feeling neutral (Figure 5). This finding unequivocally shows that instructors view mentors as a valuable resource for teaching and supporting their students.

\section{Figure 5. Course instructors' perceptions of the help provided by mentors to them and to} their students

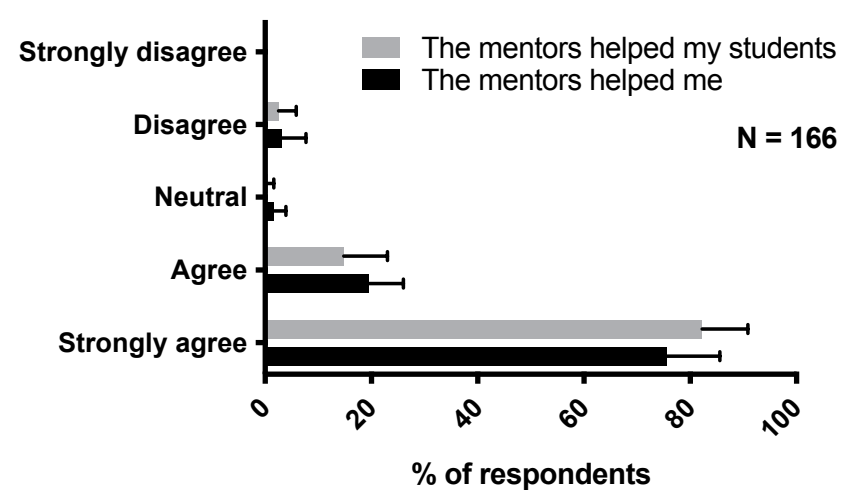

Instructors were asked to rate the statements "The TEAM mentors helped me" and "The TEAM mentors helped my students" on a Likert scale. 
The Dean of the Faculty of Science was solicited for feedback about the TEAM program, and responded the following:

"The feedback received from students, professors, and the TEAM [mentors] confirm the success of the program in engaging the learner, providing resources to course instructors, while being a rewarding and fulfilling mentorship experience for the TEAM students themselves. In fact, no week passes in which my inbox does not have five to 20 unsolicited testimonials from instructors and students as to the many positive impacts of the program. Most interesting to me are the many testimonials from the TEAM [mentors] themselves and the frequent (paraphrased) comment of 'Being a TEAM student has been the most important experience in my BSc.'" (Prof. Bruce Lennox, Dean of the Faculty of Science, McGill University)

\section{Mentors' perception of their impact on student learning}

In a feedback form sent to them at the end of the semester, TEAM mentors were asked whether they believed they had positively impacted the learning experience of the students they mentored. In response, mentors nearly unanimously (99\%) indicated that they indeed thought so. This resounding affirmation supports the TEAM program as a valuable educational program that fosters in mentors a clear appreciation for their teaching impact on their peers.

Mentors were also asked to give examples of the type of support that they believed to be most helpful to their peers. Content analysis of this data revealed that the majority of mentors (89\%) reported providing content-related support to their peers (Figure 6). This finding is expected as mentors have recently taken the course and are a valuable source of knowledge for their peers. More unexpectedly, a significant number of mentors believed that serving as an effective feedback channel between students and the course instructor or GTAs (36\%) or that serving as a relatable teaching figure in the class (22\%) positively impacted student learning. These results highlight the importance of mentors as relatable figures who help connect students to less accessible instructors. A minority of mentors reported feeling that providing emotional support to stressed peers (11\%) or improving general student enjoyment of the course (6\%) impacted student learning positively, suggesting that mentors more frequently contributed to student learning on an academic level rather than on a personal level.

Figure 6. Types of support mentors believed were helpful in positively impacting the learning experience of students 


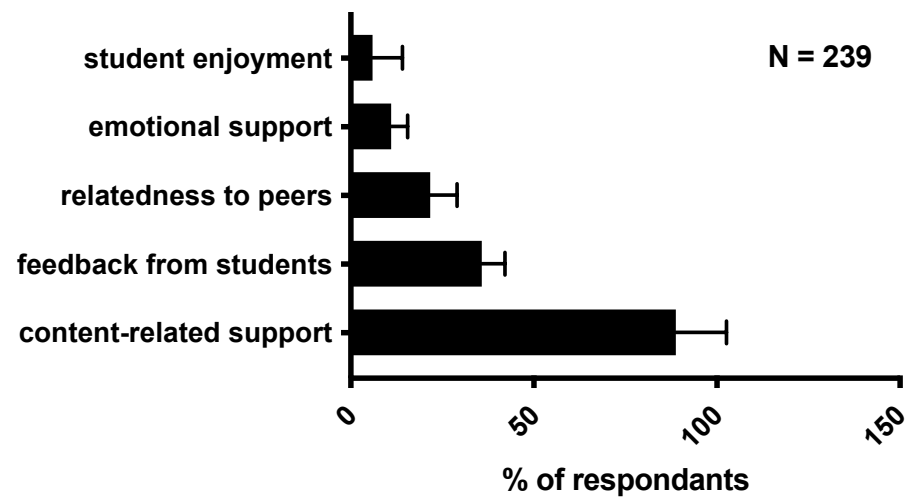

Mentors were also invited to comment on their TEAM experience. Several powerful testimonies were selected to convey the extent to which the program has contributed to creating a community, to developing teaching experience, and to supporting student learning:

- "Through assisting the students, I have understood the importance of creativity in explaining concepts, have enriched my communication skills (particularly, clarity and conciseness whilst describing reaction mechanisms), and have found this to be one of my passions. I am very thankful for this McGill Project!" (TEAM Mentor 1)

- "I hope to pursue professional and/or graduate studies in the future, and I felt that this program greatly prepared me for my experiences to come (being a TA, teaching, leading conferences, etc). I will be serving as a TEAM student again next semester and I am already greatly looking forward to the experience. Thank you SO much for the opportunity!" (TEAM Mentor 2)

- "The majority of students need an interactive and personal learning experience, especially in first- and second-year courses when the adjustment to university academics remains a significant challenge. TEAM students fulfill the role of helpers, mentors, and friends to students in their assigned courses. They almost always love to teach and are waiting for the chance to help out-and this is exactly my personal story." (TEAM Mentor 3)

These testimonies show how the TEAM experience has: (a) challenged mentors' communication or metacognitive skills in explaining material or designing questions, (b) afforded them a space to explore their creativity in teaching, (c) prepared them for future academic or professional positions, and (d) fostered a deep appreciation for their teaching and mentoring role.

\section{Students' perception of mentors' impact on their own learning}

To more directly probe the impact that TEAM mentors had on students, students were asked to reflect on the support provided by the TEAM program in end-of-semester course evaluations. Results show that the vast majority of students who interacted with mentors strongly agreed or agreed (72\%) that TEAM mentors provided valuable help in the course or the 
lab in which they were enrolled, while very few students (6\%) disagreed or strongly disagreed (Figure 7). These highly encouraging findings show that the majority of students were in strong agreement with their mentors and course instructors about the quality of the help provided by the mentors. It was also found that $44 \%$ of students reported not having interacted with a TEAM mentor throughout the semester (Figure 8). This finding is not entirely unexpected for two reasons: the large sizes of these surveyed courses make it difficult to reach all students, and certain students choose not to interact with supporting staff unless necessary or required. This indicates that better representation of mentors amongst their peers and a closer relationship with the course instructors will help increase their visibility to students.

Figure 7. Students' perception of the help provided by mentors in supporting their learning

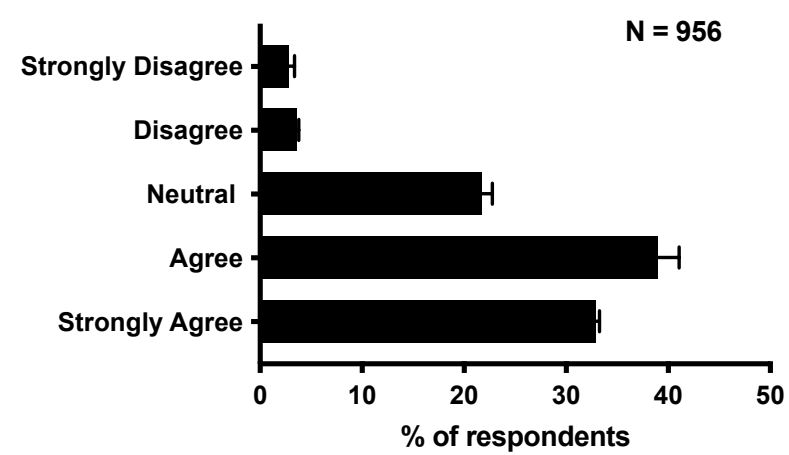

Students were asked to rate the statement "Overall, the TEAM mentors provided valuable help in the course or lab" on a Likert scale.

Figure 8. Proportion of students who have interacted with mentors in their course

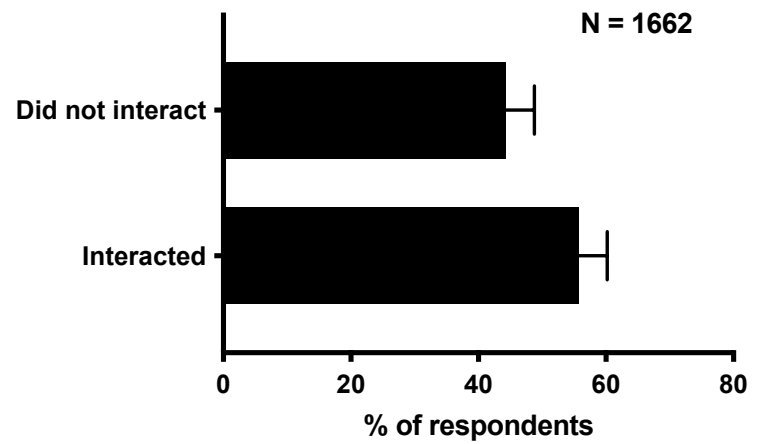

\section{CONCLUSION}

In order to improve the quality of education in large undergraduate courses, McGill University has implemented the TEAM program, a university-wide peer mentorship program which adopts the SaP framework. Our report has found that TEAM mentors participated in varied tasks that challenged either their communication or metacognitive skills in explaining material or designing assessment questions. The growth of the program directly testifies to its 
success and the need for it in the McGill community, with an overwhelming number of course instructors valuing the help of their TEAM mentors and a nearly unanimous number of TEAM mentors believing that they positively impacted the learning of their peers. These findings were corroborated by the majority of students who concurred that the TEAM mentors were helpful in promoting their own learning. Ultimately, the TEAM mentors' own testimonies regarding their impact on their peers revealed a deep appreciation for their TEAM experience. Particularly, mentors commented on the importance and development of a community, their communication skills, their creativity, and other practical skills that they believed may help them in future endeavors. Most importantly, mentors reported deriving a sense of meaning and purpose from teaching and supporting their peers, which unequivocally speaks to the success of this program, and which they will hopefully carry forward after they graduate.

This work was funded by the Tomlinson Endowment made to McGill University. ACKNOWLEDGEMENTS

In loving memory of Dan Petrescu, friend and colleague.

\section{NOTE ON CONTRIBUTORS}

Dan Petrescu is a PhD candidate in the department of chemistry at McGill University and the current lead graduate teaching fellow with the Tomlinson Project in University-Level Science Education.

Armin Yazdani is an Academic Associate and Lecturer with the Office of Science Education at McGill University and the former lead graduate teaching fellow with the Tomlinson Project in University-Level Science Education.

Cassidy R. VanderSchee completed her PhD in the department of Chemistry and was a graduate teaching fellow with the Tomlinson Project in University-Level Science Education.

Christopher A. Bailey completed his PhD in the department of Kinesiology and Physical Education at McGill University and was a graduate teaching fellow with the Tomlinson Project in University-Level Science Education.

Faygie Covens is the administrative coordinator with the Tomlinson Project in University-Level Science Education at McGill University.

Dr. David N Harpp is a Professor in the department of chemistry at McGill University. Dr. Harpp holds the Tomlinson Chair of Science Education at McGill University. 


\section{REFERENCES}

Bryson, C. (2016). Engagement through partnership: students as partners in learning and teaching in higher education. International Journal for Academic Development, 21:1, 8486. https://doi.org/10.1080/1360144x.2016.1124966

Colvin, J. W., \& Ashman, M. (2010). Roles, Risks, and Benefits of Peer Mentoring Relationships in Higher Education. Mentoring \& Tutoring: Partnership in Learning, 18:2, 121-134. https://doi.org/10.1080/13611261003678879

Crouch, C. H. (1998). PEER INSTRUCTION: An Interactive Approach for Large Lecture Classes. Optics \& Photonics News 9: 9, 37-41. https://doi.org/10.1364/opn.9.9.000037

Crouch, C. H., \& Mazur, E. (2001). Peer Instruction: Ten years of experience and results. American Journal of Physics 69: 9, 970-977. https://doi.org/10.1119/1.1374249

Crouch, C. H., Watkins, J., Fagen, A. P., \& Mazur, E. (2007). Peer Instruction: Engaging Students One-on-One, All At Once. Research-Based Reform of University Physics.

Danker, B. (2015). Using Flipped Classroom Approach to Explore Deep Learning in Large Classrooms. IAFOR Journal of Education, 3:1, 171-186. https://doi.org/10.22492/ije.3.1.10

Fagen, A. P., Crouch, C. H., \& Mazur, E. (2002). Peer Instruction: Results from a Range of Classrooms. The Physics Teacher, 40, 206-209. https://doi.org/10.1119/1.1474140

Fingerson, L., \& Culley, A. B. (2001). Collaborators in Teaching and Learning: Undergraduate Teaching Assistants in the Classroom. Teaching Sociology, 29:3, 299-315. https://doi.org/10.2307/1319189

Healey, M., Flint, A., \& Harrington, K. (2016). Students as Partners: Reflections on a Conceptual Model. Teaching \& Learning Inquiry, 4:2, 8-20. https://doi.org/10.20343/teachlearninqu.4.2.3

Hill, R., \& Reddy, P. (2007). Undergraduate Peer Mentoring: An Investigation into Processes, Activities and Outcomes. Psychology Learning \& Teaching, 6:2, 98-103. https://doi.org/10.2304/plat.2007.6.2.98

Mazur, E. (2008). Peer instruction: Getting students to think in class. AIP Conference Proceedings 399, 981-988. https://doi.org/10.1063/1.53199

Mercer-Mapstone, L., Dvorakova, S. L., Matthews, K. E., Abbot, S., Cheng, B., Felten, P., Swaim, 
K. (2017). A Systematic Literature Review of Students as Partners in Higher Education. International Journal for Students as Partners, 1:1, 1-23.

https://doi.org/10.15173/ijsap.v1i1.3119

Philipp, S., Tretter, T., \& Rich, C. (2016). Research and Teaching: Development of Undergraduate Teaching Assistants as Effective Instructors in STEM Courses. Journal of College Science Teaching, 45:3. https://doi.org/10.2505/4/jcst16 0450374

Schell, J., \& Mazur, E. (2015). Flipping the Chemistry Classroom with Peer Instruction. In Chemistry Education: Best Practices, Opportunities and Trends ( $1^{\text {st }}$ ed., pp. 319-344). https://doi.org/10.1002/9783527679300.ch13

Smith, T. (2008). Integrating undergraduate peer mentors into liberal arts courses: A pilot study. Innovative Higher Education, 33, 49-63. https://doi.org/10.1007/s10755-007-9064-6

Wheeler, L. B., Maeng, J. L., Chiu, J. L., \& Bell, R. L. (2017). Do teaching assistants matter? Investigating relationships between teaching assistants and student outcomes in undergraduate science laboratory classes. Journal of Research in Science Teaching, 54:4, 463-492. https:/doi.org/10.1002/tea.21373

Zher, N. H., Hussein, R. M. R., \& Saat, R. M. (2016). Enhancing Feedback via Peer Learning in Large Classrooms. Malaysian Online Journal of Educational Technology, 4(1), 1-16. 